\title{
EL REFERÉNDUM DE INDEPENDENCIA ESCOCÉS ${ }^{1}$
}

\author{
ALAN PAGE \\ Catedrático de Derecho Público \\ University of Dundee
}

\section{SUMARIO}

I. Introducción. II. La «devolution» y el camino constitucional hacia la independencia. III. Gobierno en minoría y «diálogo nacional». IV. La Comisión Calman. V. Gobierno mayoritario y referéndum. VI. El Acuerdo de Edimburgo. VII. La campaña del referéndum. VIII. La Comisión Smith y el proyecto de Ley para Escocia. IX. ¿Un segundo referéndum?

\section{INTRODUCCIÓN}

El 18 de septiembre de 2014 Escocia votó negativamente a la pregunta «¿debería ser Escocia un país independiente?» y, de esta forma, decidió que debería continuar formando parte del Reino Unido. El margen de victoria del resultado del «no» fue más amplio que lo que parecían anticipar los momentos finales de la campaña del referéndum, aunque no tanto como para entender que el debate sobre el futuro de Escocia dentro del Reino Unido había quedado zanjado de una vez por todas. En estas notas se tratará de explicar el proceso mediante el que se llegó a celebrar dicho referéndum y lo que ocurrió a partir de entonces.

\section{LA «DEVOLUTION»Y EL CAMINO CONSTITUCIONAL HACIA LA INDEPENDENCIA}

De acuerdo con la Constitución no escrita del Reino Unido no existe un derecho formal de secesión. No se discute, sin embargo, que Escocia tiene derecho a abandonar el Reino Unido si así lo decide, pero esto es algo que se entendía

1 Traducción de Fernando Reviriego Picón y María Salvador Martínez, Profesores Titulares de Derecho Constitucional de la UNED.

UNED. Teoría y Realidad Constitucional, núm. 37, 2016, pp. 437-448 
muy improbable hasta hace poco tiempo. La concepción del Reino Unido posterior al proceso de «devolution» es que éste continúa siendo un Estado multinacional, compuesto por varias naciones, más que un Estado con una única nación. Por ello hay coincidencia en entender que el pueblo de Escocia, o cualquier otro, no pueden ser retenidos dentro del Reino Unido en contra de su voluntad. De esta forma, si Escocia hubiera votado afirmativamente a la pregunta planteada en el referéndum, se habría convertido en un Estado independiente ${ }^{2}$.

El Partido Nacional Escocés -partido independentista- fue fundado en 1934 (como resultado de la fusión del Partido Nacional de Escocia y el Partido Escocés) pero tuvieron que pasar tres décadas más antes de que éste consiguiera una cierta entidad en las urnas. En noviembre de 1967 el partido obtuvo una agónica victoria en la ciudad de Hamilton sobre la base de exigir al entonces Gobierno laborista que creara una Comisión Constitucional «para examinar las funciones que ejercen actualmente los poderes legislativo y ejecutivo centrales respecto a los diferentes países, naciones y regiones que forman el Reino Unido» y para valorar «si es deseable algún tipo de modificación en dichas funciones o, si no, en las actuales relaciones constitucionales y económicas». La Comisión creada era consciente, no obstante, de que «el principal objetivo con el que se había constituido era el de analizar la posibilidad de transferir o devolver el ejercicio de funciones de gobierno desde el Parlamento y el Gobierno centrales a nuevas instituciones de gobierno de las diferentes países y regiones del Reino Unido» ${ }^{3}$.

La legislación para establecer asambleas electas en Escocia y Gales se desarrolló en $1978^{4}$, acompañada de un acalorado debate político, pero no llegó a crearse ninguna de ellas, puesto que en los referéndums se rechazó la propuesta de establecer un poder legislativo galés y no se obtuvo la mayoría suficiente para aprobar la propuesta de establecer un poder legislativo escocés. Veinte años más tarde, sin embargo, el Gobierno laborista de Tony Blair constituyó el Parlamento escocés y la Asamblea de Gales tras los referendos en los que la propuesta de establecer un Parlamento escocés y reconocerle competencias limitadas sobre diferentes tributos alcanzó una mayoría sustancial, y la propuesta de establecer una Asamblea de Gales obtuvo una estrecha mayoría 5 .

De acuerdo con la posición tradicional del Partido Nacional Escocés (SNP), un mandato para la independencia precisaría del apoyo de la mayoría de los parlamentarios escoceses en el Parlamento de Westminster (el parlamento del Reino

2 La Northern Ireland Act 1998 (s 1.2) establece que Irlanda del Norte no dejará de formar parte del Reino Unido sin la aprobación del pueblo de Irlanda del Norte en una votación; la consecuencia es que, si el pueblo lo aprueba, el Gobierno del Reino Unido respetará su voluntad.

3 Kilbrandon Commission, Report of the Royal Commission on the Constitution 1969-1973 (Cmnd 5460, 1973) para 13.

4 Scotland Act de 1978, Wales Act de 1978.

5 Scotland Act de 1998, Wales Act de 1998. La Asamblea de Irlanda del Norte también se estableció conforme a la Northern Ireland Act de 1998. 
Unido); sin embargo, con la creación del Parlamento escocés, este partido entiende ahora que el «camino constitucional» a la independencia exigiría una mayoría, o bien en el Parlamento de Westminster, o bien en el Parlamento escocés en Holyrood, y, además, un referéndum sobre la independencia. «El SNP abogará en estas elecciones por un compromiso explícito de celebrar un referéndum... El referéndum debería ser lo más claro posible y con una respuesta SI/NO a la decisión sobre la independencia... Si las votaciones dan un claro resultado mayoritario en uno u otro sentido, la respuesta o reacción conforme a esa decisión de los ciudadanos también será clara ${ }^{6}$. Este compromiso con el referéndum, en particular en el contexto de las elecciones al nuevo Parlamento escocés en Holyrood, permitió al SNP separar el apoyo al partido del apoyo a la independencia. «Al prometer un referéndum sobre la opción constitucional que ellos defendían, estaban ofreciendo a los votantes la posibilidad de votar al partido sin apoyar su opción constitucional. Mientras sus oponentes argumentaban que un voto para el SNP era un voto para el separatismo y la independencia (expresada peyorativamente), el SNP podía contestar que una victoria suya tendría como resultado simplemente la celebración de un referéndum ${ }^{7}$. Tal y como el SNP lo expresó en su programa a las elecciones al Parlamento escocés de 2003: «No es el Partido Nacional Escocés (...) el que va a decidir cuándo Escocia será independiente. Es el pueblo escocés quien lo hará en un referéndum que se llevará a cabo durante nuestro gobierno» ${ }^{8}$.

\section{GOBIERNO EN MINORÍA Y «DIÁLOGO NACIONAL»}

El Parlamento escocés es elegido mediante un sistema de representación proporcional, el sistema de representación proporcional mixta, a diferencia del sistema mayoritario que se utiliza en las elecciones al Parlamento de Westminster (first-past-the-post). El sistema proporcional mixto fue ideado con el objeto de evitar que un único partido obtuviera la mayoría ilimitada de escaños, pero eso no impidió que el SNP ganara con mayoría absoluta en las cuartas elecciones al Parlamento escocés de 2011, convirtiendo en inevitable la celebración de un referéndum sobre el futuro constitucional de Escocia.

Antes de ello, en las dos primeras elecciones al Parlamento escocés, en 1999 y 2003, el Partido Laborista había formado gobiernos mayoritarios de coalición con el Partido Liberal Demócrata, mientras que en las terceras elecciones, en 2007, el SNP se convirtió en el partido más votado, con cuarenta y siete escaños frente a los cuarenta y seis del Partido Laborista. El SNP formó entonces un go-

6 Maccormick, N., «Is There a Constitutional Path to Scottish Independence», 2000, 53 Parliamentary Affairs p. 722.

7 Mitchell, J., The Scottish Question, Oxford University Press, 2014, pp. 269-270.

8 SNP, The Complete Case for a Better Scotland, 2003, 2. 
bierno en minoría, ya que los liberal-demócratas se negaron a formar una coalición con este último salvo que renunciara expresamente a su compromiso de celebrar un referéndum sobre la independencia. En su programa el SNP se había comprometió a elaborar un Libro Blanco en el que se «detallase el concepto de una independencia escocesa en el mundo moderno, como parte de los preparativos para ofrecer a los ciudadanos escoceses la oportunidad de decidir sobre la independencia en un referéndum, que trataría que se celebrase en 2010».

Después de formar Gobierno, el SNP se embarcó en lo que se vino a denominar un «Diálogo Nacional» sobre el futuro constitucional de Escocia ${ }^{9}$. A juicio del Gobierno del SNP existían tres «opciones realistas». La primera, mantener el status quo establecido por la Scotland Act de 1998, con la posibilidad, en su caso, de ampliaciones concretas de las competencias del Parlamento escocés. Conforme al acuerdo de descentralización de 1998, la defensa y la seguridad nacional, la política macro-económica, los asuntos exteriores, la inmigración, la radiotelevisión, la energía, la seguridad social y las pensiones, y la constitución, eran materias que quedaban reservadas al Parlamento del Reino Unido, mientras que otras materias como la salud, la educación, la justicia, el gobierno local, la vivienda, el urbanismo, el desarrollo económico, el transporte, el medio ambiente, la agricultura y la pesca, el deporte y la cultura quedaban en manos del Parlamento escocés. La segunda opción implicaría «rediseñar la devolution otorgando mayores competencias al Parlamento y al Gobierno escocés, probablemente relacionados con la autonomía fiscal, pero sin vocación de llegar a la plena independencia». La tercera opción, que sería por la que apostaba el gobierno del SNP, consistiría en una «ampliación de competencias del Parlamento y el Gobierno de Escocia, hasta alcanzar la independencia» ${ }^{10}$.

$\mathrm{Al}$ «Diálogo Nacional» debía seguir la convocatoria de un referéndum sobre la independencia. «Como culminación de este compromiso, publicaremos un Libro Blanco en la festividad de St. Andrews de 2009. Presentaremos entonces un proyecto de ley de referéndum en el Parlamento en 2010 para que pueda celebrarse un referéndum sobre el futuro constitucional de Escocia» ${ }^{11}$. En Your Scotland, Your Voice, publicado en noviembre de 2009, el Gobierno del SNP anunció que tenía intención de celebrar un referéndum en noviembre de 2010. En enero de 2010 se publicó un informe sobre el texto del proyecto de ley escocesa de referéndum, en el que se preveían dos preguntas para el referéndum. Una primera relativa a la ampliación de competencias del Parlamento escocés, pero sin vocación de independencia; una segunda relativa a si las competencias del parlamento escocés deberían ampliarse hasta hacer posible la independencia. Sin embargo, cuando se hizo evidente que en el Parlamento escocés dicho proyecto de ley no

9 Choosing Scotland's Future: A National Conversation, agosto de 2007.

10 Choosing Scotland's Future (n 8), p. vii-viii.

11 Gobierno de Escocia, Towards a More Successful Scotland: The Government's Programme for Scotland 2009-2010, septiembre de 2009, p. 51. 
alcanzaría la mayoría necesaria para ser aprobado, el gobierno del SNP anunció en septiembre de 2010 que el referéndum no se convocaría antes de las siguientes elecciones al Parlamento, que tendrían lugar en mayo de 2011. Probablemente esto no fue entendido por el SNP como un serio retroceso, ya que su estrategia entonces estaba más dirigida a consolidar su imagen de partido de Gobierno que a asegurar la celebración del referéndum, que, además, según señalaban las encuestas, tenía pocas posibilidades de éxito en aquel momento.

\section{LA COMISIÓN CALMAN}

Los partidos de la oposición en el Parlamento de Escocia respondieron al «Diálogo Nacional» del SNP mediante la creación de una comisión sobre la «devolution» escocesa, la Comisión Calman, con el apoyo del Gobierno del Reino Unido, «para revisar las disposiciones de la Scotland Act de 1998 a la luz de la experiencia y recomendar cualquier cambio en los acuerdos constitucionales que permitiera al Parlamento escocés servir de forma más satisfactoria al pueblo de Escocia, mejorando la responsabilidad financiera del Parlamento escocés, y continuar asegurando la permanencia de Escocia dentro del Reino Unido». En su informe final, publicado en junio de 2009, la Comisión Calman recomendó: incrementar la responsabilidad financiera del Parlamento escocés a través de la introducción de un tipo escocés en el impuesto sobre la renta, que sustituyera parcialmente al impuesto sobre la renta del Reino Unido; mejorar las relaciones intergubernamentales e interparlamentarias; y realizar algunos otros ajustes menores respecto a la distribución de competencias ${ }^{12}$. Estas recomendaciones se llevaron a cabo a través de la Scotland Act de 2012, aprobada después de las elecciones al Parlamento escocés de mayo de 2011.

\section{GOBIERNO MAYORITARIO Y REFERÉNDUM}

El SNP se presentó a las elecciones al Parlamento escocés de 2011 con un compromiso renovado, aunque atenuado, de proponer la celebración de un referéndum en el siguiente período de sesiones del referido Parlamento: «Entendemos que el pueblo de Escocia debe decidir el futuro de nuestra Nación a través de un referéndum democrático y las encuestas indican que la mayoría de los escoceses están de acuerdo con ello. Nosotros, por tanto, seguiremos adelante con nuestro proyecto de ley de referéndum en el nuevo Parlamento» ${ }^{13}$. Como ya se ha dicho, el sistema electoral escocés se diseñó con objeto de evitar que un único par-

12 Serving Scotland Better: Scotland and the United Kingdom in the $21^{\text {st }}$ Century, junio de 2009.

13 SNP, Re-elect a Scottish Government Working for Scotland, 2011, p. 28.

UNED. Teoría y Realidad Constitucional, núm. 37, 2016, pp. 437-448 
tido pudiera tener una mayoría cualificada, pero, para sorpresa del propio SNP, y de sus adversarios políticos, éste consiguió mayoría absoluta, obteniendo sesenta y nueve de los ciento veintinueve escaños parlamentarios, y haciendo inevitable la celebración de un referéndum sobre el futuro constitucional de Escocia.

Antes que el referéndum pudiera celebrarse, había que decidir una serie de cuestiones. La más importante era determinar si dentro de las competencias legislativas del Parlamento escocés se encontraba la de legislar para la celebración del referéndum, dado que la unión entre los reinos de Escocia e Inglaterra era una «materia reservada», es decir, sobre la que tenía competencia sólo el Parlamento de Westminster ${ }^{14}$. En un dictamen publicado en enero de 2012, siete meses después de las elecciones, el Gobierno del Reino Unido cuestionaba que jurídicamente el Parlamento escocés tuviera el poder de autorizar un referéndum sobre la independencia, pero se ofreció a legislar sobre ello para alejar cualquier duda en este sentido y garantizar que el resultado de la consulta fuera «legal, fiable y decisivo» ${ }^{15}$. Consideramos que no es favorable a los intereses de nadie.... que haya un proceso de referéndum susceptible de ser cuestionado jurídicamente con todos los retrasos y la incertidumbre que ello implicaría; asimismo, somos optimistas en el sentido de creer que podemos alcanzar un resultado justo y legítimo para las dos posiciones enfrentadas existentes, así como para el pueblo de Escocia en su conjunto» ${ }^{16}$.

El Gobierno del SNP respondió con su propio dictamen, en el que declaraba su disposición a trabajar con el Gobierno del Reino Unido para eliminar las dudas que éste tenía acerca de la competencia legislativa del Parlamento escocés, y de este modo evitar posibles recursos a los tribunales, pero al mismo tiempo insistió en que cualquier modificación o alteración de las competencias legislativas del Parlamento escocés debería hacerse sólo con el consentimiento de ambos Parlamentos, y sin condición alguna: «El mandato electoral hecho al Gobierno de Escocia para la celebración de un referéndum es claro. Corresponde por tanto al Gobierno proponer al Parlamento escocés el calendario y las condiciones de la consulta, así como las normas según las cuales se celebrará. Es el Parlamento escocés quien deberá decidir estas cuestiones ${ }^{17}$.

También se plantearon otro tipo de cuestiones, como el número de preguntas a plantear en la papeleta de votación (el Gobierno del SNP quería plantear una segunda pregunta abierta sobre la conveniencia de atribuir mayores competencias al Parlamento escocés, de modo que, como denunciaron sus oponentes, así podía evitar el fracaso que supondría no obtener la mayoría en la respuesta a una primera pregunta directa sobre la independencia); la fecha de la consulta (el Gobierno del Reino Unido quería que fuese lo antes posible, mientras que el SNP prefería retrasarlo con el objetivo de contar con más tiempo para intentar dar la

14 Scotland Act 1998, sch 5, pt I, para 5(b).

15 Scotland's Constitutional Future (Cm 8203, 2012).

16 Cm 8203 (n 14) Preámbulo.

17 Gobierno de Escocia, Your Scotland, Your Referendum, enero de 2012, Sumario. 
vuelta a las encuestas que parecían otorgar mayor apoyo al no a la independencia); y la edad exigida para participar en la votación (el SNP quería extender a los jóvenes de dieciséis y diecisiete años el derecho de sufragio).

\section{EL ACUERDO DE EDIMBURGO}

Finalmente, se llegó a un acuerdo entre los dos gobiernos para proponer la aprobación de un decreto conforme a la sección 30 de la Scotland Act con el objeto de autorizar la celebración de un referéndum que constaría de una sola pregunta sobre la independencia de Escocia, y que tendría lugar antes de finalizar $2014^{18}$. El decreto alejaba cualquier duda sobre la potestad del Parlamento escocés para legislar sobre este referéndum. El Gobierno escocés tenía que ser quien presentase ante el Parlamento escocés el proyecto de ley sobre el referéndum de independencia; así lo hizo y el resultado fueron dos leyes de 2013: la Scottish Independence Referendum (Franchise) Act y la Scottish Independence Referendum Act. En el memorando del acuerdo, y en el proyecto de decreto, en los que se recogen los detalles del acuerdo, los dos gobiernos demostraron su voluntad de que el referéndum fuera «legal y fiable, cuyo resultado fuera decisivo y respetado» ${ }^{19}$. También afirmaron su compromiso de «continuar trabajando juntos de manera constructiva conforme a los resultados del referendum, cualesquiera que fuesen, en interés del pueblo de Escocia y del resto del Reino Unido ${ }^{20}$.

\section{LA CAMPAÑA DEL REFERÉNDUM}

La campaña oficial para la celebración del referéndum comenzó a finales de mayo de 2014, aunque en realidad ya había comenzado desde el mismo momento en que se produjeron las primeras desavenencias entre los dos gobiernos, a principios de 2012, acerca de si el Parlamento escocés tenía o no competencia para celebrar un referéndum. Fueron numerosas las cuestiones debatidas en campaña, aunque especialmente destacada fue la relativa a las consecuencias económicas de un resultado u otro en el referéndum. Desde el sector favorable a la independencia se afirmaba que Escocia podría incrementar las cifras de su economía en cinco mil millones de libras al año en un plazo de quince años tras la independencia $^{21}$; desde el lado contrario se señalaba que Escocia recibiría un «dividendo

18 Acuerdo entre los Gobiernos de Reino Unido y Escocia para la celebración de un referendum sobre la independencia de Escocia, Edimburgo, 15 de octubre de 2012.

19 Acuerdo (n 17) par. 30.

20 Acuerdo (n 17) par. 30.

21 Gobierno de Escocia, Outlook for Scotland's Public Finances and the Opportunities of Independence, mayo de 2014, p. 48.

UNED. Teoría y Realidad Constitucional, núm. 37, 2016, pp. 437-448 
del Reino Unido» de mil cuatrocientas libras por persona anualmente en el caso de permanencia en el mismo ${ }^{22}$.

En estrecha relación con la cuestión de si Escocia estaría en una mejor o peor situación económica si se convirtiera en un estado independiente, se discutió sobre el tema de la moneda: los partidarios del No argumentaban que una Escocia independiente no podría usar la libra esterlina como parte de una unión monetaria formal con el resto del Reino Unido, mientras que desde el lado del SI afirmaban que estaban convencidos de que el acuerdo alcanzado no se truncaría por el tema de la moneda. Pero es muy difícil creer que la ausencia de un Plan B en esta materia, de una alternativa real a una unión monetaria formal, no iba a perjudicar a la opción del SI.

Otro tema muy destacado que se abordó durante la campaña fue la cuestión de las consecuencias respecto de la permanencia o no en la Unión Europea de una Escocia independiente, esto es, si seguiría o no formando parte Escocia de la misma o resultaría preciso iniciar un proceso de adhesión como nuevo Estado.

Durante buena parte de la campaña no parecían existir dudas sobre el resultado final del referéndum. Sin embargo, mientras iba transcurriendo la misma, el lado del SI fue haciendo progresos reduciendo la distancia que le separaba del sector contrario a la independencia. En la recta final de la campaña había menos confianza que al principio de que el NO fuera a ganar. De hecho, el margen con el que ganó el NO fue más amplio del que se pensaba en los momentos del cierre de campaña (un cincuenta y cinco por ciento en contra de la independencia y casi un cuarenta y cinco por ciento a favor, con una participación de casi el ochenta y cinco por ciento de los electores), pero no tan amplio como para entender que la cuestión del futuro de Escocia en el Reino Unido se había sido resuelto de una vez para siempre.

\section{LA COMISIÓN SMITH Y EL PROYECTO DE LEY PARA ESCOCIA}

En las negociaciones entre los dos gobiernos sobre el referéndum, el Gobierno del SNP intentó, aunque no lo consiguió, que se incluyera una segunda pregunta en la papeleta en la que se consultase de forma abierta sobre la atribución de mayores poderes para el Parlamento escocés; como se ha dicho, los oponentes al SNP entendieron que así éste se aseguraba no salir del referéndum con las manos vacías en el caso de que la respuesta a la pregunta sobre la independencia fuese negativa. "Aunque el Gobierno escocés tiene como principal objetivo la independencia, reconoce que existe un considerable respaldo entre los escoceses a un incremento de los poderes y responsabilidades del Parlamento, pero sin llegar 
a la independencia. El Gobierno escocés tiene clara esta cuestión..., por ello tiene la voluntad de incluir una pregunta en el referéndum sobre una ampliación de la «devolution». Esta sigue siendo la posición del Gobierno de Escocia» ${ }^{23}$. El Gobierno del Reino Unido, sin embargo, se mantuvo firme en que sólo una vez tomada la decisión de la permanencia de Escocia en el Reino Unido podría abrirse el debate sobre la atribución de mayores competencias al Parlamento escocés. Con unas elecciones generales en el Reino Unido en el horizonte, a celebrarse en mayo de 2015, el planteamiento fue que los trabajos sobre el tema de la ampliación de competencias, en el caso de que ganase el NO, solo podrían iniciarse después de esas elecciones generales, momento en el cual habría comenzado la cuenta atrás para las elecciones al Parlamento escocés de mayo de 2016. En los días finales de la campaña del referéndum, sin embargo, cuando los sondeos ofrecieron cifras muy parejas para las dos posiciones enfrentadas, los líderes de los tres principales partidos políticos en Westminster se comprometieron a ofrecer nuevas competencias al Parlamento «mediante el procedimiento y conforme al calendario anunciado por los tres partidos y que comenzaría de forma inmediata al día siguiente del referéndum, el 19 de septiembre ${ }^{24}$; mayoritariamente se considera, con acierto o no, que este compromiso terminó por sellar la victoria del NO en la campaña del referéndum.

El proyecto de Ley para Escocia, la Scotland Act, fue presentado tras la victoria del partido conservador en las elecciones generales del Reino Unido en mayo de 2015. Dicho proyecto incorporó los trabajos y recomendaciones de la Comisión Smith, una comisión creada por el Primer Ministro inmediatamente después del referéndum, en la que participaron diferentes partidos y que tenía el objetivo de acordar la ampliación de competencias al Parlamento escocés ${ }^{25}$. Conforme a las disposiciones del proyecto, el Parlamento escocés y el Gobierno escocés se convierten en órganos permanentes- un asunto más complejo de lo que pudiera parecer a primera vista en virtud de la constitución no escrita del Reino Unido y a causa de la doctrina de la soberanía del parlamento, según la cual ningún parlamento puede vincular a parlamentos posteriores, ni siquiera a sí mismo, en el sentido de impedir que un parlamento pueda modificar una decisión parlamentaria anterior, y esto significa que nada impediría que el Parlamento de Westminster pudiera posteriormente eliminar el Parlamento o el Gobierno escocés o modificar sus poderes. En una versión posterior, el proyecto de ley establece que el Parlamento Escocés y el Gobierno de Escocia son «una parte permanente de los acuerdos constitucionales del Reino Unido», antes de declarar que «no serán abolidos, salvo que así lo decidiera el pueblo de Escocia en un referéndum».

23 Your Scotland, Your Referendum, n 16 , pp. 5-6.

24 Daily Record, 16 de septiembre de 2014.

25 Report of the Smith Commission for further devolution of powers to the Scottish Parliament, noviembre de 2014. El informe de la Comisión fue seguido de la publicación de las cláusulas de 22 de enero de 2015: Scotland in the United Kingdom: an Enduring Settlement (Cm 8890, 2015). 
Desde la doctrina constitucional, como es obvio, se sigue argumentando que el Parlamento del Reino Unido conserva la facultad de abolir el Parlamento y Gobierno escocés sin necesitar la decisión de la ciudadanía en un referéndum a estos efectos. Pero la realidad política, que el proyecto de ley refleja, es que el Parlamento y el Gobierno escocés son parte del consenso y del orden constitucional del Reino Unido y lo seguirán siendo en tanto que Escocia permanezca dentro del mismo.

Los poderes del Parlamento escocés se verán incrementados, convirtiéndose, a los ojos del gobierno del Reino Unido, en «uno de los parlamentos devolved (fruto de un proceso de «devolución») con mayores competencias del mundo». Entre los nuevos poderes a atribuirle se cuentan relevantes competencias en materia de Estado del bienestar, hasta ahora una materia reservada a Westminster, así como competencias fiscales adicionales a las que se le atribuyeron en virtud de la Scotland Act de 2012. Así, el Parlamento escocés tendrá la facultad de fijar la tasa del impuesto de la renta del Reino Unido y los umbrales de tributación para los ingresos que no provengan del ahorro ni de rentas del capital de los contribuyentes escoceses. Otros impuestos (como las tasas aeroportuarias y las tasas medioambientales por utilización de aglomerados de arena y rocas) serán también transferidos, y los primeros diez puntos porcentuales de la tasa general del IVA recaudado en Escocia se asignarán al presupuesto del Gobierno escocés.

Estas cifras no se incluyeron en la Comisión Smith, pero se estima que, como resultado del acuerdo, el Parlamento de Escocia controlará cerca del sesenta por ciento del gasto en Escocia y se quedará con alrededor del cuarenta por ciento de los ingresos fiscales de Escocia; ${ }^{26}$ la diferencia entre una cifra y otra permanece en manos de la Hacienda del Reino Unido.

Los cambios propuestos en el acuerdo de «devolución», resultado del trabajo de la Comisión Smith, no se limitaron al ámbito legislativo. La Comisión vio cómo se incrementaron las competencias del Parlamento escocés como consecuencia de la demanda de fortalecer la colaboración entre los gobiernos de Escocia y el Reino Unido: «Los partidos creen que los mecanismos intergubernamentales actualmente existentes entre los gobiernos de Escocia y el Reino Unido, incluidas las Comisiones intergubernamentales (Joint Ministerial Committee -JMC), deben ser reformadas con carácter de urgencia y ampliadas significativamente en orden a reflejar el alcance del acuerdo al que han llegado los partidos» ${ }^{27}$. En una recomendación personal añadida al informe, Lord Smith, Presidente de la Comisión, instó a los dos gobiernos a abordar la cuestión del «débil trabajo intergubernamental». La situación actual «con un reforzado Parlamento escocés y un acuerdo de «devolución» más complejo exige abordar este problema. Ambos gobiernos necesitan 
trabajar juntos para establecer una relación más productiva, sólida, visible y transparente. También es necesario que haya un mayor respeto entre ellos». En la sesión plenaria del Joint Ministerial Committee de 15 de diciembre de 2014, los Ministros acordaron encargar una versión revisada del Memorándum de Acuerdo que rige las relaciones entre el Gobierno del Reino Unido y las administraciones devolved $^{28}$. Un rasgo característico de los actuales acuerdos y disposiciones en la materia es que forman parte de las normas no escritas del Reino Unido. Como demuestra el tratamiento propuesto para otros elementos del acuerdo de «devolution», no hay ninguna razón que impida reconocer, regular e institucionalizar, también las relaciones intergubernamentales, y de hecho habría mucho que decir sobre su reconocimiento, como «una parte permanente de los acuerdos constitucionales del Reino Unido».

\section{IX. ¿UN SEGUNDO REFERÉNDUM?}

El referéndum fue calificado por el SNP durante la campaña como una «oportunidad única en una generación». No obstante, lo cierto es que tan pronto se conocieron los resultados se abrió el debate sobre las circunstancias bajo las cuales podría celebrarse un nuevo referéndum. El éxito del SNP en las elecciones generales del Reino Unido de 2015, donde obtuvieron cincuenta y seis de los cincuenta y nueve escaños de Escocia, parece crear nuevamente los mimbres que llevarían a un segundo referéndum. Pero la constatación de que el apoyo a la independencia todavía permanece por debajo del cincuenta por ciento en los sondeos, unido al hecho de que la pérdida de un segundo referéndum sacaría definitivamente el tema de la independencia de la agenda política, ha llevado al SNP a reorientar sus prioridades, estableciendo como primer objetivo la obtención de la mayoría de los escaños del Parlamento escocés en las elecciones de mayo de 2016, un objetivo que no parece inalcanzable dado los problemas que el Partido laborista, su principal rival en estos comicios, tiene en estos momentos. Por lo que respecta a ese segundo referéndum, se ha dicho que un nuevo referéndum exigiría «un cambio sustancial de las circunstancias»; para el SNP, como ya ha afirmado en su conferencia anual, ese cambio se produciría si se diese un porcentaje sesenta-cuarenta en las encuestas en favor de la independencia durante un período superior a un año. Parece, por tanto, poco probable que se pueda producir un segundo referéndum hasta que el SNP tenga la seguridad de que puede ganarlo. Hasta entonces, y mientras tanto, el SNP ha propuesto una enmienda a la Scotland Bill que otorgara al Parlamento

28 Cabinet Office, Memorandum of Understanding and Supplementary Agreements between the United Kingdom Government, the Scottish Ministers, the Welsh Ministers, and the Northern Ireland Executive Committee, octubre de 2013 .

UNED. Teoría y Realidad Constitucional, núm. 37, 2016, pp. 437-448 
escocés el poder de decidir el calendario de las futuras consultas, aunque parece muy poco probable que esta propuesta resulte finalmente aprobada.

$* * *$

TITLE: The Scottish Independence Referendum

AвSTRACT: On 18 September 2014 Scotland voted No in answer to the question: 'Should Scotland be an independent country?', and in so doing decided that it should remain part of the United Kingdom. The margin of victory for the No side was wider than had seemed likely in the closing stages of the referendum campaign, but not so wide as to suggest that the question of Scotland's future within the United Kingdom had been settled once and for all. This article explains how Scotland got there and outlines what has happened since.

Resumen: El 18 de septiembre de 2014 Escocia votó negativamente a la cuestión "¿Debe ser Escocia un país independiente?"; de esta forma decidió continuar formando parte del Reino Unido. El margen de victoria del resultado del «no» fue más amplio que lo que parecían anticipar los momentos finales de la campaña del referéndum, aunque no tanto como para sugerir que la cuestión del futuro de Escocia dentro del Reino Unido había sido decidido de una vez para siempre. En estas notas se tratará de explicar el proceso mediante el que llegó a celelebrar dicho referéndum y lo que ocurrió a partir de entonces.

KEY WORDS: Scotland. Referendum. Independence.

Palabras Clave: Escocia. Referéndum. Independencia.

FECHA DE RECEPCión: 07.11.2015 FECHA DE ACEPTACión: 15.01.2016 